\title{
Visualizing War? Towards a Visual Analysis of Videogames and Social Media
}

\author{
Nick Robinson and Marcus Schulzke
}

\begin{abstract}
Political scientists are increasingly engaged with the importance of the "visual turn," asking questions about how we understand what we see and the social and political consequences of that seeing. One of the greatest challenges facing researchers is developing methods that can help us understand visual politics. Much of the literature has fallen into the familiar qualitative versus quantitative methodological binary, with a strong bias in favor of the former, and has consequently been unable to realize the advantages of mixed-methods research. We advance the study of visual politics as well as the literature on bridging the quantitative versus qualitative divide by showing that it is possible to generate quantitative data that is rooted in, and amenable to, qualitative research on visual phenomena. Our approach to conducting mixed-methods research is an alternative to the more common strategy of seeing various research methods as an assortment of tools, as it is directed at developing an organic relationship between qualitative and quantitative methods. We demonstrate the effectiveness of this strategy for research on visual politics by discussing our own efforts to create a dataset for quantifying visual signifiers of militarism.
\end{abstract}

T he world is becoming ever more visual. The evocative power of images was evident throughout the Cold War (e.g., the destructive capacity of nuclear weapons was demonstrated through images of mushroom clouds); and images were instrumental in reducing Americans' appetite for war in Vietnam. More recently, images from Abu Ghraib, Islamic State's beheadings, cartoons of the prophet Muhammad, the protests in

A list of supplementary materials provided by the authors precedes the references section.

Nick Robinson is Associate Professor in Politics and International Studies, School of Politics and International Studies, University of Leeds,UK (N.Robinson@leeds.ac.uk). His research focuses on the militarization of social media and the politics of videogames, with specific focus on military games. Marcus Schulzke is a Lecturer in the Department of Politics at the University of York, UK (marcus. schulzke@york.ac.uk). His primary research interests are security studies, contemporary political theory and the political dimensions of new media. This paper has been generously funded by a fouryear Framework Grant from the Swedish Research Council as part of its programme, "The Digitized Society—Past, Present, and Future." Their own project, "Militarization 2.0: Militarization's Social Media Footprint Through a Gendered Lens" involves project partners from Sweden (Susan Jackson, Stockholm University), the UK (Nick Robinson, University of Leeds), and Germany (Jutta Joachim, Leibniz University Hannover and Andrea Schneiker, University of Siegen).
Ferguson, and the young Syrian refugee who drowned on a Turkish beach in September 2015 have all been seen as decisive in reframing political and social debates. All of these examples are integrally related to visual warfare, whether focused on the battlefield, on the victims of war, or on militaristic policing. The visuality of politics has become more pronounced with the explosive circulation of images, particularly on and through social media.

Integral to contemporary war is its visual articulation. Since the first Gulf War, the public has increasingly experienced war through television news coverage, popular culture, and entertainment. All of these forms center on visual spectacle-what Roger Stahl refers to as "militainment." In the popular cultural realm, military videogames, for example, are played by millions of people in North America, Europe and Australasia: five of the last six games in the Call of Duty series have each sold approximately 25-30 million copies, grossing revenues of over $\$ 1$ billion each. As Stahl identified, these are not isolated cases: "September 11, 2001 and the ensuing wars in Afghanistan and Iraq ushered in a boom in sales of war-themed video games for the commercial market." Concurrent with this move to visual war has been the growth of social media as a platform and agent for the circulation and consumption of images, films and promotional videos centred on war and military recruitment. We serve here to aid increased understanding of the growing visual politics of war.

Perhaps paradoxically, the growing interest in visual politics and political violence has coincided with a decline in academic interest in studying militarism. ${ }^{3}$ In making 
this claim, we take Anna Stavrianakis and Jan Selby's definition of militarism - "the preparation for, and conduct of, organized political violence" — and following John Gillis, we see militarism as "either the dominance of the military over civilian authority, or, more generally as the prevalence of warlike values in society." ${ }^{4}$ Militarism thus centres on organised, state-driven activity.

This paradox is particularly curious as militarism is often given purchase through visual signifiers within the realm of everyday politics, whether through the production of popular culture simulations of war, the public celebration of the military at sporting events, or the media's coverage of attacks, which is presented as visually spectacular entertainment. A further paradox is that there should be a relatively muted interest in militarism within political science scholarship given the growth of state-sanctioned and instigated violence and the significant interest in both the study of war and violence more generally. We seek to address the shortfall of existing work on visual politics and militarism by examining a key site of popular culture's encounter with war: the promotional advertisements produced for military videogames as hosted on social media.

The large and rapidly expanding literature on visual politics is a testament to the political importance of visuality. Studies of visual politics have explored dozens of ways in which visual experiences help to construct politics. Those focusing on militarism have reached particularly important insights by showing how these media may influence national and international security in ways that discourage critical inquiry and perpetuate delusive security discourses. ${ }^{5}$ We take this work as our starting point for an analysis of military videogame advertisements. We are not aware of any previous effort to study these advertisements, and we contend that this is a serious oversight. The videos we discuss sit at the intersection of several different types of militaristic entertainment (videogames, social media, and television) and are designed to sell the experience of war to consumers. These videos-all of which are hosted on social media - are integral to the marketing campaigns of military videogame producers and have important implications for everyday militarism.

With an estimated 3.2 billion Internet users worldwide, new media in the form of Web 2.0 applications and their user-generated content increasingly rivals traditional media as a means of gathering information. ${ }^{6}$ As James Der Derian points out, "the informational, technological as well as political networks of global media require new modes of comprehension and instruction, and scholars have not been very quick to take up the challenge." ${ }^{7}$ Since this observation, there has been an impressive growth of scholarship within the field of politics and IR, yet much of it is restricted to examining social media as an agent of political change-most particularly see the initially optimistic literature on the Arab Spring-or focused on the ethical and normative concerns in relation to the control exercised by states over the internet and the circulation of data. ${ }^{8}$ We expand the existing scholarship, seeing social media as both a site of politics and as a method for politics research.

In the context of the importance of social media, the military videogame advertisements we analyze also attract huge audiences. As of June 1, 2015, the videos included in our dataset had a combined total of 666,618,965 views on the developers' YouTube channels. When one includes the dozens of places where the videos are reposted, including other users' YouTube channels (which sometimes attract even more attention than the originals), that number rises to over a billion. It is likely that many readers - even those who have never played military videogames-will have seen some of these advertisements, as they regularly appear on television around the world.

We argue that the best way to understand the power of these videos in the context of accounts of visual politics, militarization, and the politics of the everyday is to bridge the gap between quantitative and qualitative analysis. To this end we are strongly influenced by the thinking of Roland Blieker, who explicitly sets out to bridge divisions between scholars who hold divergent epistemological and ontological positions:

If a puzzle is the main research challenge, then it can be addressed with all means available, independently of their provenance or label. A source may stem from this or that discipline, it may be academically sanctioned or not, expressed in prose or poetic form, it may be language based or visual or musical or take any other shape or form; it is legitimate as long as it helps to illuminate the puzzle in question. ${ }^{9}$

We take Bleiker's insight seriously, focusing on the visual turn in political science. In our terms, the "puzzle" is how we understand the signifiers of militarism that we see in entertainment media and social media. Our goal is to make substantive and methodological contributions. We simultaneously advance the study of visual politics and efforts to develop effective mixed-methods research by highlighting the importance of militaristic entertainment media and providing a strategy for overcoming the qualitative versus quantitative divide that hinders the progress of research on visual politics.

Although studies of visual politics have made many important discoveries, they tend to be constrained by the qualitative versus quantitative methodological divide. The strong preference for qualitative research has resulted in an extremely valuable literature exploring the meaning of individual texts or small numbers of texts. However, researchers rarely attempt to take a broader perspective to address the patterns that persist across large numbers of texts. This casts doubt on the extent to which qualitative studies' findings can be generalized and raises questions about what visual information may only become meaningful when it is seen in the context of representational patterns. Bridging the methodological divide has been one of the central aims of work on research methodology for 
decades, and some noteworthy efforts have been made to develop effective mixed-methods approaches. ${ }^{10}$ The typical strategy is to treat various methods as "tools" that can be deployed independently or in conjunction to address a research problem. ${ }^{11}$ This strategy may be appropriate in many instances, but it raises serious concerns when it is applied to visual phenomena and social media, which may seem to resist quantification. We contend that the quantitative analysis of visual phenomena must arise organically from qualitative approaches. We show that coding - the process of transforming qualitative visual information into quantitative data-can be done in a way that is highly-sensitive to qualitative research concerns.

We offer two methodological contentions. First, much aesthetic work employs concepts that are clearer and more explicit than may be expected; it offers an "inferred sense of clarity." Qualitative researchers may provide an explicit sense of what they regard as important when they undertake either visual or narrative analysis. We contend that much qualitative literature actually does work with assumptions that certain signifiers of militarism are integral to affect. Second, we see coding as (perhaps surprisingly) more compatible with a qualitative approach than may be expected (even among those who support methodological pluralism), ${ }^{12}$ allowing us to capture "what we see" and "how we look" - to permit greater, not lesser, qualitative insight. What we are aiming to do is to use our coding schema to reveal how present such signifiers are (e.g., representations of gender) and to raise questions about how things that are ascribed affective importance are actually present in very different ways depending on the phenomenon under consideration. The key insight that makes this approach to quantification possible is that the process of generating numbers must be grounded in a qualitative approach and its sensibilities. Quantification must be undertaken as part of a continuum of research strategies, rather than as a different kind of tool. When it comes to visuality and social media, quantification must also be seen as a style of interpretation and not as a way of reaching a purely objective viewpoint.

We proceed in several interrelated steps. First, we explore some prominent examples from the literature on visualities of militarism to demonstrate that much of it works with an implied focus on seeing with precision. We argue that this depends on identifying clear signifiers, many of which are amenable to quantification. Second, we reflect on the concept of militarism to demonstrate that studies of the visualities of militarism often rely on clear signifiers that can be represented numerically. Third, we articulate a method of coding visual information that can be based on the signifiers identified in the qualitative literature. Thus, the data we generate arises organically from the qualitative literature and speaks to the same interests. Finally, we provide an overview of a codebook that we designed to capture the content of visual media (here, videos designed to promote military videogames as hosted on YouTube) as an example of what an organicallygenerated dataset may look like and what substantive insights it can reveal.

\section{The Visual Politics of Militarism}

Much of the literature on visual politics is directed at tracking the visualities of militarism. This is an especially popular and important subset of visual analysis for political scientists because militarism addresses fundamental political issues, including appropriate uses of force, civil-military relations, foreign policy, and the international balance of power. As Gillis says, militarism is "usually defined as either the dominance of the military over civilian authority, or, more generally, as the prevalence of warlike values in society." 13 And as Stavrianakis and Selby point out, militarism is surprisingly understudied within politics and IR because "sustained research and reflection has largely disappeared since the 1990s." ${ }^{14}$ Given the growth of political violence the dearth of scholarship in this area is "paradoxical." ${ }^{15}$ To address this shortfall, they offer a five-fold typology of militarism which covers: ideology (the celebration and glorification of war); behavioral (the use of force to resolve disputes); military build-ups (measuring the growth of military budgets, equipment, or personnel); institutional conceptions (the links between the military and government), and sociological understandings (the embeddedness of militarism within society). Offering a preference for a sociological approach, which they argue can in principle capture all of these other elements, ${ }^{16}$ they emphasize the importance of greater methodological work to study militarism. ${ }^{17}$ With our specific focus on capturing signifiers of visual militarism, we explicitly seek to speak to this agenda.

Åhäll usefully differentiates between militarism and militarization, with the former "an open, visible and conscious display of militaristic ideology," whereas the latter is a "much more subtle process of the normalisation of a militarised society," 18 forming a "set of social relationships organized around war and preparation for war." ${ }^{19}$ Militarism (unlike militarization) is thus observable through both the structural power of the military but also in the active promotion of militaristic solutions to political problems. ${ }^{20}$ It is this notion of "active promotion" that allows us to identify signifiers of militarism.

Integral to militarism is its visual articulation with a particularly acute manifestation captured in the work on spectacular war, which emphasizes that since the first Gulf War, war has increasingly been presented to the public as a form of spectacle. ${ }^{21}$ Mediated through television news coverage with war presented as a technologically driven "festival of fireworks and machinery," ${ }^{22}$ spectacular war further accelerates a move away from "what war has been-a violent engagement between antagonistic bodies" - towards "a clinical slaughter in which one side's technological superiority insulates the warriors from the 
traditional vulnerabilities of direct combat." ${ }^{\text {23 }}$ For Stahl, reporting on war has increasingly begun to resemble sports coverage, flicking between news anchor and highlights, utilizing specific scenes for "slow motion instant replay," whilst "military experts provided color commentary." 24

Spectacular war took on an arguably even more pronounced aspect with the events of 9/11 (initially through the repeated images of the fall of the Twin Towers) but the subsequent war on terror "was in part communicated by and made meaningful through visual representation." 25 Shepherd discusses the power of the images of torture at Abu Ghraib, which "became the dominant representation used in 'mainstream media' of the U.S. presence in Iraq, replacing the previously widely reproduced image of the toppling of the statue of Saddam Hussein," thus decisively shaping perceptions of that war.

Concurrent with a focus on concerns in relation to the growth of militarism in society has been an increasing acknowledgement of the importance of the interrelationship between popular culture and the military. ${ }^{26}$ Matt Davies and Simon Philpott's discussion of militarism and popular culture is particularly important here, providing a comprehensive analysis that teases out the different roles popular culture performs and presenting a call for further research. ${ }^{27}$ Davies and Philpott find that although militarism is pervasive and invades virtually every dimension of social life, its influence is probably most obvious in films. They argue that "fictional film has been a popular way for audiences to inform, entertain and educate themselves about global politics" and that films' engagement in militarism makes them a threat to democratic public life. ${ }^{28}$ They go on to offer a range of other examples of militarism becoming infused in our visual experiences, such as the fashion of wearing military clothing. They also highlight the importance of video games in disseminating militaristic imagery, saying that they are "the most recent popular culture form in which the logics of militarization have been evident." 29

Klaus Dodds also gets at the subject of militarism in a study of films about the war on terror, which are "capable of reflecting but also challenging certain norms, structures and ideologies associated with U.S. foreign and security policies and the ongoing war on terror."30 He supports this claim with a series of examples of how the war on terror is constructed in popular films, as well as examples of how real political actors engaged in that war have explicitly drawn rhetorical support from films. ${ }^{31}$ As is typical of studies of militaristic popular culture, Dodds analyses these films qualitatively and focuses on providing close readings of a relatively small number of cases. The result is that, while he develops a strong account of how films contain tropes reflective of the war on terror, it remains unclear how representative his findings are of militaristic films more generally and the extent to which other film genres may be affected by themes that appear in films about the war on terror.

Militaristic videogames have emerged as a particularly important object of visual analysis over the past decade. Much of the scholarship examines the messages that appear in military games, demonstrating how they differentiate between the player's allies and the enemy, often positioning the latter as a "rogue state" beyond the boundaries of reason and diplomacy, so legitimating the use of overwhelming force. ${ }^{32}$ Vit Šisler's work is typical of this literature, offering a reading that demonstrates that military games typically contain stereotypical representations of Muslims. He argues that whereas U.S. or allied troops are "humanized and individualized," with playable and non-playable characters portrayed having "nicknames or specific visual characteristics," the enemy is "collectivized and linguistically functionalized as 'various terrorist groups,' 'militants,' and 'insurgents." 33 Furthermore, player characters and their allies are often portrayed as morally righteous, professional, and courageous, whereas the enemy is "presented in a way that suggests they are not 'real' soldiers, thereby removing the legitimacy of their actions."

Johan Höglund also maintains that military games are guilty of portraying Orientalism, with players cast in a pattern of "perpetual war" in which they are charged with asserting control over a dangerous other. ${ }^{35}$ Frequently the allies are portrayed as a multi-lateral force (a coalition of the willing), so justifying the rhetoric of a war on terror with the Middle Eastern enemy seen as requiring near continuous military intervention and restraint. Overall, then, this literature emphasizes that American military games contain a narrative that is based around justifiable violence to vanquish the country's enemies. As Steven Poole notes, these games rely on a shoot-and-destroy mechanic and promote a highly problematic assumption that complex social and political problems such as the "war on drugs" or the "war on terror" can be solved militarily: "the more naturalistic videogames become in their modes of representation and modelling of real-life phenomena, the more they will find themselves implicated in political questions, and will need to have their ideology interrogated."36

The consequences of this increasing portrayal of war as entertainment may suggest a move towards an increasingly soporific citizenry that becomes progressively disengaged, no longer questioning why we fight, instead losing "itself in the fact that we fight." ${ }^{37}$ Yet they are in fact seen to demonstrate a variety of responses from "distraction, bedazzlement and voyeurism" (a soporific "citizen spectator" in Stahl's terms) to being positively mobilised to actively support military action (a "virtual citizen soldier" engaging in "interactive war" as Stahl puts it). ${ }^{38}$ The public are thus not necessarily passive receptors of media imagery-they are not "absorbent sponges" in Colin McInnes' terms-but remain capable of independent thought and judgement. ${ }^{39}$ The "sport" element of his 
metaphor explains this variation and refers to the degrees of engagement with war by the public (as in sports, the public varies from passive and unmoved to obsessive engagement).

This summary of the work within popular culture and world politics cannot hope to do justice to the diversity of this research. What we hope it shows, however, is that much of it places considerable emphasis on the importance of identifying how popular culture is integral to the promotion of militarism within contemporary society. These studies of the visualities of militarism, and others like them that we discuss later, have made valuable discoveries and have introduced sophisticated theoretical insights. They are evidence that qualitative methods should continue to have a central place in research on visuality and militarism. Nevertheless, as we will show, this research is artificially limited by the restricted methodological strategies that are employed. Studies that focus on a small set of cases remain open to accusations of being "extreme cases" or "atypical instances" of militarism even if they are not. Fortunately, this criticism can be overcome by using the qualitative literature as the basis for designing a quantitative dataset, so allowing for the exposure of patterns that exist across militaristic media.

\section{The Visual Turn in Political Science}

Over the past two decades political science has gone through what is often called "the visual turn" - a shift marked by greater attention to images in all contexts and to popular culture in particular. ${ }^{40}$ This shows a profound respect for the role that images have in constituting politics across various domains, and has given rise to a diverse assortment of studies showing the importance of images and visual popular media in everything from teaching students about politics, ${ }^{41}$ to understanding the development of international relations research, ${ }^{42}$ to accounting for how political actors use media in an effort to influence audiences. ${ }^{43}$ As Gillian Rose points out, images are integral to the "cultural construction of social life," ${ }^{44}$ which by extension means that images help to constitute the cultural dimensions of politics.

Images are not neutral representations but rather an avenue for political action and for reflecting on political experiences. John Protevi contends that visual phenomena may operate politically by circumventing cognitive processes and reaching viewers on affective or physiological levels_-a possibility that he vividly demonstrates with case studies that show how intense emotional responses can cause, or be caused by, political decisions that incorporate visual components. ${ }^{45}$ Such indirect visual effects would be impossible to gauge with opinion polls and surveys, which call for cognitive reflection, but Protevi's claims have immense intuitive appeal. It is difficult to imagine seeing images of violence and death without experiencing some kind of affective response that can shape our thinking about war and militarism. The militaristic images that we are interested in are especially relevant because they often incorporate real political actors. Feldman correctly argues that political enemies help to constitute our identities through opposition, yet real enemies are not always present and must sometimes be imagined in an effort to stabilize identities that could otherwise become precarious. ${ }^{46}$ Images are one of the primary venues through which this is done, as evidenced by the dozens of military videogames that use historical or fictional conflicts as settings in which to celebrate American values and a highly-militarized vision of American identity.

The heterogeneous assortment of research agendas that constitute the visual turn is evidence of the broad political significance of visual phenomena. Nevertheless, despite this topical diversity, research on politics and visuality remains constrained by methodological divisions that reflect those within politics research more broadly. Perhaps the most serious and pervasive constraint on visual analysis is an aversion to research methods that at first glance seem to be inherently positivistic. Many of the qualitative researchers who are interested in visual phenomena engage in close readings of individual texts or small numbers of texts, focusing on things like reader experiences, affect, and authorial intent. It could be assumed that much of this research would seek to avoid using any kind of large-N analysis on the basis that it would in someway "violate" these images by first transforming them into numbers and then interpreting them as abstract correlations. There is good reason for this attitude. At first glance, the quantitative versus qualitative divide seems to be nearly insurmountable when it comes to research on visual politics because of the importance of subjective experiences in imbuing images with meaning.

The most common mixed-methods research strategy is to think of different types of methods as tools that researchers have on hand in their personal research toolboxes. ${ }^{47}$ From this perspective, "research methods are in a sense tools of analysis," ${ }^{48}$ which provide "specific research procedures and practices" 49 that can be deployed, either independently, or in conjunction, to analyze a particular phenomenon from various angles. Here the goal is to engage in a kind of cost-benefit analysis of the methods available and to choose those that provide the best "trade-offs that arise in the design of research." ${ }^{50}$ Yet for critics it seems inappropriate to apply research methods as different types of tools in this context, as this may neglect the importance of subjective experiences in constituting the meaning of visual imagery. For example, Amel Ahmed and Rudra Sil argue that it is potentially misleading to combine methods that are rooted in divergent ontological and epistemological assumptions, as qualitative visual analysis and quantification arguably are. ${ }^{51}$ 
Here we reject a bifurcation of methods that we contend poses a serious obstacle to our understanding of visual phenomena. Visual analysis should ideally be able to benefit from the different types of insights that can be reached with both types of research working in tandem. Qualitative research, whilst alive to issues such as affect and adept at offering deep interpretation, tends to be far more focused on key cases that are defined by the researcher as important objects of study, but which may be overvalued because of the disproportionate attention given to them. ${ }^{52}$ By contrast, quantitative research can help to uncover patterns of visual representation that would be extremely difficult to capture from a qualitative perspective. Mixed-method strategies that seek to deploy research "tools" have ably pointed out these respective benefits and have correctly argued that qualitative and quantitative strategies are both valuable. ${ }^{53}$ However, when it comes to visual analysis, these benefits cannot be realized without a more effective way of integrating these strategies and of clearly demonstrating that quantitative research is sensitive to the interests that are expressed in the qualitative literature on visual politics.

\section{The Strange (?) Case of Seeking Clarity in the Visual}

A small body of work on visual analysis has called attention to the need for greater methodological diversity. Most notably, Bleiker argues that it is possible for researchers to bring together qualitative and quantitative approaches, albeit without reconciling their underlying epistemological and ontological differences. He says that "using methods as diverse as discourse analysis and quantitative surveys can only be done if each of these methods is given the chance to work according to its own logic." ${ }^{54}$ The inference here, therefore, is that individual methods can work together in spite of these potentially conflicting logics. Although we share Bleiker's desire for methodological pluralism, we would go further, not only to argue for plural methods but that plural thinking can and should penetrate to the very heart of individual methods, so challenging the very logics at their heart. We contend that it is possible to reconcile research methods and their underpinnings because of their shared interest in seeing with precision. Despite the narrow focus of qualitative research on visual militarism, many studies are attentive to the need for precisely categorizing visual phenomena and explicit in articulating how one should look at the media being investigated. ${ }^{55}$ This provides a basis for a qualitatively inspired coding process that can capture militaristic imagery.

In a perceptive qualitative analysis of photographs of North Korea, David Shim attempts to provide a clear sense of how he engaged with the photographs: "In considering images as parts of a broader set of representations, methodological attention will be paid to the actual content of images, the context and conditions of their production and their relationships with and to accompanying texts and narrations." ${ }^{" 56}$ Cumulatively, Shim offers the insight that what we are shown and how we are allowed to look are critical to our conceptions of the North Korean "other." " The crucial point, of course, with analysis of photographs and other static images is that their static nature allows (subject to copyright) the reproduction of the image, and potentially its context, by the researcher. The consequence is to allow for the reader to be offered analytical engagement with the actual image and its associated text or graphics. ${ }^{58}$

Shim's desire to offer clarity in how we look and what we study and privilege as political scientists is also captured by Laura Shepherd in her 2013 book, Gender, Violence and Popular Culture. She offers a narrative focus encompassing spoken language (i.e., textual engagement with the script, song lyrics, captions, and graphics, etc.), body language (i.e., the physical performance of each character and the framing of the on-screen images and characters), and nonlinguistic signifiers (i.e., visual tropes, the built environment, lighting, music, etc. $)^{59}$ Her book thus sets out to offer precision in what she is looking at and how she is seeing and hearing when she watches a collection of TV series to demonstrate that "gender and violence are mutually constitutive of identities, relationships, (world) politics, and each other."

Linda Åhäll and Stefan Borg also set out their method of engaging with 24 , a television series that achieved fame for promoting a highly militaristic response to terrorism. ${ }^{61}$ Their approach is to utilize the concepts of predication, presupposition, and subject positioning to inform their discourse analysis, so enabling them to discuss how "certain subjects are ascribed or denied agency and, thereby, enable or disable certain practices" in relation to "the normalization of torture, the feminization of international law and the prioritization of pre-emption rather than response." ${ }^{22}$ They then use these concepts to illustrate how Jack Bauer, the lead character, is contrasted with other key figures in 24 and how torture is depicted as efficient and effective in the fight against terrorism. This focus on a conceptual-driven encounter with popular culture is quite common within visual political analysis. ${ }^{63}$ Yet unlike Åhäll and Borg, Shepherd and Shim, it is fair to say that in most cases, scholars are somewhat imprecise in terms of articulating what they are doing when they are engaging with popular culture, failing to explain how they are looking and hearing and what signifiers they are privileging.

Each of these studies takes a distinctly qualitative perspective. They do not attempt to quantify signifiers, nor do they apply any quantitative analysis techniques to the information that is present in the texts. Nevertheless, the methods of qualitative visual analysis presented in these studies provides a foundation for thinking about 
how signifiers could be quantified. We contend that the clear articulation of militaristic visual signifiers in the qualitative literature can provide a guide for a coding process that is grounded in qualitative research interests. In the following sections, we illustrate the possibility of establishing an organic relationship between qualitative and quantitative research by discussing our own efforts to develop a large- $\mathrm{N}$ dataset that tracks signifiers of militarism in videogame advertisements.

\section{Capturing Visual War-Coding Militarism}

Our strategy for reconciling qualitative and quantitative research on visual politics can be best appreciated by considering how it works in practice. We created the Military Videogame Advertisement (MVA) dataset ${ }^{64}$ as a tool for visual analysis that is grounded in qualitative research on militarism and that is openly interpretive in its approach to data collection, but that will provide a broader perspective on how militaristic themes persist across a range of different texts. The qualitative literature on visual politics influenced MVA by identifying the universe of analysis and the variables. Previous work on the design and production of quantitative datasets, as well as qualitative research that clearly articulates procedures for identifying and looking at important visual signifiers, informed our procedures for data collection.

We proceed from the same underlying assumptions as those driving qualitative research projects on visual militarism. Our dataset strikes the balance that Schedler calls for between measurement and judgment, ${ }^{65}$ as we attempt to measure visual phenomena even as we acknowledge the role our judgments play in identifying the phenomena that are meaningful and organizing them into categories. Our quantification is not meant to assert that there is a fixed truth underlying the images that interest us, but rather to develop "rules of translation" 66 that make our subjective judgments as explicit as possible. Our approach toward mixed-methods research treats qualitative and quantitative methods as being organically related, such that they are interdependent when deployed in conjunction, rather than being instrumentally related as tools. We also agree with Claudia Aradau and Jef Huysmans in thinking that "methods are not techniques of representation that simply extract information from externally given worlds while leaving the worlds they represent untouched, ${ }^{\prime 67}$ but rather interpretive techniques that produce distinctive forms of knowledge. Because our variables are derived from the qualitative literature on visual politics and operate according to the same methodological assumptions, they provide a foundation for realizing the benefits associated with quantitative analysis-most notably providing more comprehensive and systematic coverage of visual representations of war-without requiring the endorsement of truth claims and empiricist assumptions that many poststructuralist theorists of visuality either avoid making or explicitly reject.

\section{The Scope of Visual War-The Universe of Analysis}

Films, video games, and social media are regularly identified as being crucial sites of militarism in the qualitative literature. ${ }^{68}$ The MVA dataset recognizes the importance of these three types of media, as it includes videos that were used to promote video games on social media. Some videos resemble films in their style of presentation and use of human actors, while others are more akin to games because they focus on gameplay and players' experiences. All of the videos were hosted on YouTube and reflect the developers' efforts to construct a particular image of their games and the military activities they simulate. The transmedial character of the dataset adds to its usefulness by making it possible to gauge militarism in texts that are likely to be strongly affected by it. This also makes the dataset useful as a potential guide for coding visual signifiers across various types of media.

The MVA dataset is currently comprised of 520 film/video promotional advertisements and trailers for fifty of the top selling military videogames as hosted by the game-makers on their own YouTube channels. Some notable titles include Call of Duty: Advanced Warfare (released in 2014; 19.8 million units sold; 103,660,816 views), Battlefield 4 (released in 2013; 12.67 million units sold; 77,636,741 views), and Call of Duty: Black Ops 2 (released in 2012; 28.69 million units sold; 109,527,431 views). We limited our analysis to military videogames, which we define as games representing armed conflicts involving real or fictional human violent actors fighting in the twentieth or twenty-first centuries. This excludes games about distant past or future conflicts and those involving non-human opponents, such as monsters or aliens. Defining the universe of analysis in this way allows us to focus on the games that most explicitly contribute to the visual construction of contemporary war and militarism.

\section{Visualizing War-Choosing How to See}

MVA's variables are primarily based on the visual signifiers of militarism that have been identified in previous research on militaristic imagery, and militaristic video games in particular. Those signifiers are typically related to geography, technology, gender, nationality, and conceptions of enmity. Although the signifiers are usually identified in case-study research, they can also be coded to provide a quantitative perspective on how the same visual phenomena appear across a range of texts. Rather than attempting to code signifiers based on preconceptions about what is appropriate for quantitative research, we considered which signifiers that were important in the qualitative literature were also amenable to quantification. Our focus is on 
visuality, but we also included variables for tracking textual and auditory experiences and qualitative descriptions. We tracked textual information by recording transcriptions of each video, as well as including variables that identify the narrator(s)' gender, the narrator(s)' identity, and any explicit claims of realism that are made in the videos. The auditory experience was recorded by identifying the music that accompanied each of the videos-a task that was facilitated by music analysis services like Midomi and Shazam. Finally, some of the variables that are more difficult to code are accompanied by qualitative descriptions. These descriptions reflect the interpretive nature of our work, demonstrate our effort to clearly articulate how we understand visual phenomena, and acknowledge that some information can only be captured qualitatively.

The variables are organized into several categories. The first category deals with Video Type Variables, which situate the video contextually by recording information like what game is shown, when the game was released, who developed it, when the video was released, how many likes and dislikes it has, how long it is, and the number of views it has. Next, the Aesthetic Variables track the video's presentation style, gameplay perspective, and use of visual effects. These variables are meant to give some sense of how the video shows the game world and how it situates the advertisement's viewers as well as the game's players. The more-theoretically interesting variables appear in the other categories, which are worth considering in detail to appreciate 1) the theoretical benefits of visual analysis and 2) how the qualitative literature can identify quantifiable signifiers.

\section{Capturing Spatial War-The Geographies of Violence}

Much of the research on militarism takes a geographical perspective, emphasizing the pervasiveness of war in spheres of ordinary life ${ }^{69}$ and showing how certain perceptions of space reinforce militarism and associated conceptions of empire or neocolonialism. ${ }^{70}$ Dodds' comments on the geographical dimensions of militarized popular media are particularly important, as he calls attention to the political significance of setting events in one location or another:

The role and representation of places is critical to this creative process: the battlefields of Iraq, the mountains of Afghanistan, the detention centre in North Africa, the political offices in Washington, the military bases in the USA and elsewhere and, finally, the domestic spaces of U.S. and foreign homes play a critical role in shaping the identities of the protagonists and the events associated with the war on terror. Iconic buildings such as the White House frequently stand for certain assumed understandings of the USA (as homeland) and values such as freedom and liberty. Places are not simply backdrops to the development of film narratives, rather they perform a critical role in the making of these films and their subsequent engagement by viewers. ${ }^{71}$

Thus, Dodds correctly recognizes that space is not merely an empty area in which action occurs; it helps to constitute a text's narrative and visual meaning. This informed our thinking about the importance of geographical and temporal spaces in which the video-game promotional videos are set and led us to develop variables that track the various terrains and time periods that are shown in military videogame advertisements.

Research on militarized urban spaces is a particularly important subset of the literature on the geographies of militarism. As Stephen Graham points out, the representation of urban spaces of war shows the military intruding into ordinary life. "The first key feature of the new military urbanism is the way it normalizes new imaginations of political violence and a whole spectrum of ambient threats to 'security' which centre on the everyday sites, spaces, populations and circulations of cities. ${ }^{72}$ Similarly, Matthew Thomson notes an important distinction between films and military videogames in terms of their utilisation of urban settings: "with the exception of Full Metal Jacket (1987), it is hard to think of a Cold-War war film in which urban combat is depicted. In the computer games of today, however, as urban warfare becomes the default medium for fighting in reality, so it has become the default setting for operations in computer games." 73

MVA's Setting Variables recognize the importance of visual signifiers related to geography, as the variables cover a broad range of physical, temporal, and political characteristics that frame the scenes of combat shown in the videos. Variables include the type of physical location, the number of locations included, the time period, the type of conflict shown, whether the game is based on real or allegorical conflict, the appearance of urban spaces, and what conflict motives are identified. These variables will yield a number of important insights. First, they will call attention to the geographical dimensions of simulated war, including the extent to which various environments are shown as being militarized and the scope of the fighting. Second, they will make it possible to quickly identify which videos participate in the "construction of public memory" ${ }^{\text {" }}$ about real conflicts and which are set in alternate realities. Third, the Setting Variables will indicate the extent to which the videos show the kind of decontextualized glorification of war and combat that is common in recent war films. ${ }^{75}$

\section{Techno-centric and Clean War? Capturing Military Equipment and Violence}

Studies of militarism frequently call attention to the extent to which the technologies of war are celebrated with images that demonstrate their efficacy. ${ }^{76}$ This, Stahl argues, is a disconcerting theme in militaristic entertainment because the glorification of weapons discourages critical evaluation of those weapons and the ways they are used: "The repeated inscription of these values onto high-tech weaponry dispatches the process of democratic deliberation with the 
material fact of the weapon in all of its self-justifying glory." ${ }^{, 7}$ Others have likewise expressed concern that popular media help to create a false impression that weapons like drones and guided missiles are precise and inflict few civilian casualties. ${ }^{78}$ Military video games give players the chance to experiment with an assortment of simulated weapons ranging from rifles and grenades to drones and stealth aircraft. Weapons, especially those that are new and technologically sophisticated, are glorified through visual representations that attest to their power. ${ }^{79}$

Many of the weapons that appear in games are exact copies of, or at least analogous to, real weapons that are in development or that may be developed in the near future. Showing these weapons in a positive light gives them the appearance of being necessary for countering future threats, despite the ethical and legal concerns that they may raise. As Marcus Power says, "arguably, the integration of military technology into the world of entertainment 'trains' consumers to take on a militarized, aggressive stance." ${ }^{80}$ Thus, video games are one of the primary sites in which civilians gain some awareness of military technologies and it is one in which those technologies are generally presented in an uncritical light.

Military Equipment Variables, which include the weapons and vehicles used by the videos' protagonists and antagonists as well as any references to real arms producers, provide evidence of the type of actors who are involved in the simulated fighting and how combat is being represented. MVA tracks the types of weapons and vehicles that are featured in the videos and is particularly attentive to games that show controversial new weapons, such as unmanned aerial vehicles. It also records any overt references to real arms producers. Here we are particularly interested to see what technological asymmetries may exist between opposing sides, whether real weapons are featured prominently, and the extent to which the videos display the "technofetishism" that Stahl identifies as being one of the three tropes of militainment. ${ }^{81}$

The Violence Type Variables are closely related to the Military Equipment Variables, as they are designed to gauge the nature of the combat depicted in the videos. These variables give special attention to acts that might be legally or morally questionable. These variables include information like whether there are any scenes of illegal violence, what type of illegal violence is shown, whether civilians are present in the videos, how civilians are represented, whether civilians are victimized, and what civilian structures are represented as sites of war. These variables will provide a greater sense of whether military videogame advertisements represent war as a legally or ethically questionable activity, whether they acknowledge the civilian costs of war, and whether they confront these issues as a way of demonizing enemies or in ways that are potentially more critical.

\section{Visualizing Friends and Enemies-Actor Variables}

Qualitative studies of militarized popular media have found that these help to construct enemies by identifying certain groups as hostile and creating simplistic caricatures of them. At times, the construction of enemies is closely linked to real threats. Jack Holland discusses the way an episode of The West Wing that was released soon after the $9 / 11$ attacks did this by attempting to inform viewers about terrorism. ${ }^{82}$ Although the episode was ostensibly educative, it described terrorists as figures who want to kill all American citizens, whose grievances are unjustified, and who are a barrier to freedom. Other studies of militarized popular culture have reached similar conclusions about the ways in which enemies are defined as being inherently antagonistic figures with no legitimate motives. ${ }^{83}$ Qualitative studies of military video games have been particularly emphatic about this point, finding many instances in which enemies are constructed according to distorting narratives. ${ }^{84}$ This led us to include variables that track the types of entities shown as protagonists and antagonists, as well as the names of any real political entities that are shown in the games. We also included variables relating to illegal and unethical violence that are used to demonize enemies.

Militaristic media are usually intensely nationalistic. They do not simply promote war or military service but do so in the interest of a particular state and its armed forces. Thus, many studies of militarism emphasize the ways in which nationalistic and militaristic themes emerge in conjunction. ${ }^{85}$ In the United States, recent disillusionment with the wars in Iraq and Afghanistan, combined with a demand to "support the troops" at all times, has led to a subgenre of war media that demonstrate this. Several studies have critiqued films like Black Hawk Down (2001) and Behind Enemy Lines (2001) for uncritically celebrating American soldiers without evaluating the political controversies surrounding the wars that they are engaged in. ${ }^{86}$ These types of films, and other texts that similarly urge audiences to support the troops without giving much thought to why they are fighting, sustain nationalism by separating it from other considerations and by suggesting that soldiers, who are held up as the paragons of virtue, are inherently good. With this in mind, we included a variable that identifies whether a video makes displays of nationalism and a qualitative description field that allows us to describe how nationalism is represented in each instance.

\section{Militarized Masculinities, Femininity and War-Capturing Gender}

The gendered themes in military popular media are often singled out for special attention in studies of visual politics. Researchers have found extensive links between conceptions of masculinity and femininity, as well as gender roles and representations of war. ${ }^{87}$ For example, Mia Fischer says of the military commemorative events at NFL games that 
"with very limited depictions of female service members, police officers, and fire fighters, these commemorative ceremonies accentuate hyper-muscular, paternal masculinities, and a neoconservative ideology in which masculinity is associated with heroism, bravery, violence, and aggression." ${ }^{88}$

Video games show a similar pattern of gendered representations and provide a model for our approach to quantifying gender in military videogame advertisements. Studies of gender representations typically count the number of male and female characters in video games, ${ }^{89}$ in gaming magazines, ${ }^{90}$ box art, ${ }^{91}$ or advertisements. ${ }^{92}$ They also quantify the different ways of portraying male and female characters. Tracy Dietz records each instance in which a game includes females as victims, as opponents, as sexual objects, or as "action characters." ${ }^{\text {93 }}$ Monica Miller and Alicia Summers introduce a more complex categorization that includes things like the emotions characters display, the number of special abilities they have, and whether their clothing is revealing. ${ }^{94}$ The MVA dataset takes a similar approach, counting the numbers of male and female characters, the numbers of male and female players, the number of female combatants, and representations of women as civilians.

The Gender Variables track several visual characteristics that are meant to give a rough sense of the relative presence of male and female figures in the advertisements. MVA tracks the numbers of male and female players and characters, the total numbers of players and characters, and the number of female combatants. It also includes a space for a qualitative description of the way gender is represented in the video. This is meant to provide a greater sense of what the numbers indicating male and female inclusion mean in each video and to provide a record of the significant visual aspects of gendered representation that cannot be quantified.

\section{Capturing Visual War-Data Collection Procedures}

The MVA data was collected by watching a video, usually at a reduced speed, and coding the information that is relevant to particular variables. Some of the variables are naturally quantitative. For example, there are four variables that track the numbers of female and male characters and players. The numbers can be obtained by watching each video four times (once for each variable) and counting the numbers of characters and players that can be visually identified as male or female. Other variables are more challenging and require the transformation of qualitative information into numerical values. For example, the types of weapons that appear in the video are tracked with numerical codes. These codes, which include 1 for small arms, 2 for military vehicles, and 5 for aerial drones, are assigned arbitrarily to the visual signifiers. However, they are important to the dataset, as these numerical identifiers make it possible to notice patterns in the types of weapons that appear throughout the videos, such as the growing prevalence of videos featuring drones. The same is true for other variables that are not naturally quantitative and that have numbers assigned to them to represent visual signifiers.

The coding process included several steps. First, a video had to be located on the developer's YouTube page and basic information about the game and the video was recorded, such as when the game and video were released, how many views the video had, how many likes and dislikes it had, and when the video was watched by the coder. Second, the video was downloaded for storage and to allow the coder to watch it using a media player with playback speed controls. Many of the variables could only be reliably coded at a much slower speed than how they are normally shown, as the videos tend to be fast paced and rapidly switch between angles and scenes. Third, the coder watched the video one or more times for each variable to see whether the signifiers related to that variable were present or absent.

Once finished, the data went through quality control checks. These started with a random sample of 15 percent of the videos being coded by another person using the same codebook, but without seeing the original data. This is consistent with intercoder reliability checks that are used in datasets on political violence, which typically recode a small subset of randomly selected cases. ${ }^{95}$ For example, the BFRS Political Violence in Pakistan Dataset re-coded 10 percent of the cases included. ${ }^{96}$ Additionally, we agree with Rose that the goal of visual analysis is not to uncover truth but rather to reach justified interpretations. ${ }^{97}$ The intercoder reliability checks are framed with this goal in mind, as they are meant to ensure that the primary coder's interpretations are supported by the available evidence and not as a way of eliminating subjective experience from the data collection process. Whenever conflicts between the original coding and the verification coding arose, they were resolved by a third member of the research team. The quality control phase then moved on to consistency checks to ensure that there was no missing or contradictory information. This left us with data that reflected the coders' subjective interpretations of what visual signifiers were important but that was nevertheless rigorously applied to ensure that judgments were fairly consistent across the videos.

\section{Conclusion}

In an increasingly visual age in which politics is frequently consumed by citizens in highly visual ways-typically through social media, mass media, or popular culturethe need to gain a sense of the importance of visualities is ever more pressing. This need becomes even greater when we consider that so few of us now have direct experience of war or the military. War is now increasingly experienced by its citizens remotely, mediated to them through 24-hour 
rolling television news coverage, popular culture, and social media. Central to this experience is a focus on highly visual coverage, with war presented as a spectacle centered on the usage of ever-more powerful and technologically sophisticated remote weapons systems.

Guided by the growing significance of visuality in world politics, the rise of militarized popular culture, and the importance of social media, we have sought to show the benefits of expanding the scope of political science research and taking a more systematic approach to interpreting images. Our hope is that this can provide a starting point for a more pluralistic approach to studying visualities, social media, and militarism, either on their own or as the related concepts that they are in our analysis. As we have shown, a reengagement with the importance of visuality, social media, and militarism is essential because of the extent to which these concepts provide us with information about the world and help us construct the meaning of events.

Social media are one of the most pervasive modes of transmitting visual information, and often give images greater weight by making them available to audiences around the world and lowering the costs of reaching those audiences. And militarism is inscribed in the images we consume in social media, from reporting on far away wars to videos marketing conflict as a source of entertainment.

This research agenda is particularly important now, as political science has been slower to confront these areas of research than other social science disciplines and needs to be more attentive to some of the emerging research questions associated with new media. There has been an impressive growth of scholarship on new media in recent years, yet much of it remains focused on either examining social media as an agent of political change- see most particularly the initially optimistic literature on the Arab Spring_or to discuss ethical and normative concerns in relation to the control exercised by states over the internet and the circulation of data. ${ }^{98}$ Unfortunately, divisions have also arisen between scholars who are interested in issues related to visuality and social media and those who pursue more mainstream research agendas. Given that so many visually-inspired political scientists complain of the marginalizing of their work as relatively unimportant within the mainstream, the benefits of collaboration across methodological divides become clearer.

Inspired by Bleiker's desire to offer a problem-centric approach to research, we have begun the task of opening up what we hope is a fruitful dialogue between quantitative and qualitative research in the study of visual politics. In taking this step we are mindful that there could be initial resistance from both camps. To assuage such resistance we have offered what we hope is a productive way of unifying qualitative and quantitative methods. Beginning with the insight that much qualitative work from within the "visual turn" does actively seek to offer clarity to researchers in terms of how people couldlshould see, we contend that this desire to seek precision in how we look can be productively captured via coding. In suggesting 'coding the visual' to qualitative researchers, however, we see it less as a tool for large-n quantitative analysis and more as a tool to aid them in gaining another way of affirming findings that alternatively can be all too easily dismissed as atypical or based on gut reactions. We side with qualitative research in rejecting such charges and thus advocate coding to support and affirm their findings. Yet we would also like to suggest that in offering this step into coding that quantitative researchers will also be able to see a bridge towards qualitative analysis, much of which is explicitly sensitive to the need for identifying clear visual signifiers. Given that so many visuallyinspired political scientists complain of the marginalizing of their work as relatively unimportant within the mainstream, the benefits of collaboration across methodological divides become clearer. To that degree, we hope that we go some way to suggesting a path forward and to responding to Bleiker's call, and through that, reaffirm the central role of visual politics and visual militarism.

\section{Notes}

1 Stahl 2010.

2 Stahl 2006, 118.

3 Stavrianakis and Selby 2012, 3.

4 Gillis 1989, 1.

5 Amoore 2007; Shepherd 2008; Stahl 2009.

6 International Telecommunications Union 2015, 1.

7 Der Derian 2009, 5.

8 See, for example, Gunitsky 2015 on the moves by authoritarian states to suppress, co-opt and proactively control the internet and Hood 2011 on debates regarding Wikileaks.

9 Bleiker 2003, 420.

10 King, Keohane and Verba 1994; Henry and Collier 2006; Barakso, Sabet and Schaffner 2014; Berg-Schlosser 2012.

11 Marsh and Stoker 1995; Geddes 2003; Mahoney and Goertz 2006; McNabb 2010.

12 See Bleiker 2015.

13 Gillis 1989, 1.

14 Stavrianakis and Selby 2012, 3.

15 Ibid., 4.

16 Ibid., 14.

17 Ibid., 15.

18 Åhäll 2015, 68, emphasis added.

19 Ibid., 66-7.

20 See also Bacevich 2005, 227.

21 See, for example, Baudrillard 1995; McInnes 2002; Andersen 2006; Stahl 2010.

22 Stahl 2010, 35.

23 Shapiro 2013, 142.

24 Stahl 2010, 51. See also McInnes 2002.

25 Shepherd 2008, 213. 
26 See, for example, Boggs and Pollard 2006, 2007; Der Derian 2009.

27 Davies and Philpott 2012.

28 Ibid., 5.

29 Ibid., 53.

30 Dodds 2008b, 1624-5.

31 Dodds 2008b.

32 Chan 2005; Power 2007; Šisler 2008; Dyer-Witheford and de Peuter 2009; Huntemann and Payne 2009; Mantello 2012; Schulzke 2013c, 2014; and Robinson 2015.

33 Šisler 2008, 208.

34 Ibid., 208.

35 Höglund 2008.

36 Poole 2004.

37 Stahl 2010, 31.

38 Ibid., 42. See also Andersen 2006, 244; McInnes 2002, 143-52; Robinson 2016.

39 McInnes 2002, 146.

40 Lacy 2001, 2003; Kellner 2004; Dodds 2007; Amoore 2007; Dalby 2008, Shaw 2010; Dittmer 2010.

41 Gregg 1998, 1999; Weber 2001.

42 Rowley and Weldes 2012; Robinson 2015.

43 Kellner 2004; Boggs and Pollard 2006; Shepherd 2008; Schulzke 2012, 2013b, 2014.

44 Rose 2012, 2.

45 Protevi 2009.

46 Feldman 2009.

47 Geddes 2003; Collier and Brady 2004; Brady and Collier 2006; Marsh and Stoker 1995; McNabb 2010.

48 Halperin and Heath 2012, 20.

49 Brady, Collier and Seawright 2004, 7.

50 Ibid., 10.

51 Ahmed and Sil 2012, 939.

52 Mahoney and Goertz 2006.

53 Collier and Brady 2004.

54 Bleiker 2015, 874.

55 Rose 2012.

56 Shim 2014; 39. See also Rose 2012; Hansen 2011.

57 Shim 2014, 39-44, 46.

58 See, for example, Dodds 2007 on Steve Bell's cartoons and Hansen 2011 on the Danish cartoons crisis. The former reproduces a number of cartoons, whereas Hansen produces a hyperlink (63) to the original images.

59 Shepherd 2013, 7-11.

60 Shepherd 2013, x. See also Rowley 2010, 314-8.

61 Åhäll and Borg 2013.

62 Ibid., 196, 202.

63 See also Shapiro 2009, 2013; Weber 2006, 2014.

64 A copy of the codebook and coding guide are hosted online at http://marcusschulzke.webs.com/data.

65 Schedler 2012.

66 Ibid., 21.

67 Aradau and Huysmans 2013, 603.
68 Power 2007; Dodds 2008a, 2008b; Shapiro 2009; Robinson 2012; Rech 2014.

69 Lutz 2002; Bernazzoli and Flint 2010.

70 Dyer-Witherford and De Peuter. 2009; Shaw 2010; Schulzke 2013c.

71 Dodds 2008b, 1625.

72 Graham 2012, 138.

73 Thomson 2009, 99.

74 Hess 2007.

75 Wetta and Novelli 2003; Stahl 2010.

76 Lutz 2002; Der Derian 2009; Stahl 2010.

77 Stahl 2010, 28.

78 Zehfuss 2011, Salter 2014.

79 Kundnani 2004; Stahl 2010; Maradin 2013.

80 Power 2007, 284.

81 Stahl 2010.

82 Holland 2011.

83 Van Veeren 2009.

84 Šisler 2008; Schulzke 2013a.

85 Orr 2004; Stahl 2009; Gonzales 2010.

86 Wetta 2003; Weber 2006; Stahl, 2009.

87 Howardiff and Prividera 2008; Sjolander and Trevenen 2010.

88 Fischer 2014, 18.

89 Dietz 1998; Beasley and Collins Standley 2002; Jansz and Martis 2007.

90 Miller and Summers 2007.

91 Provenzo 1991.

92 Scharrer 2004.

93 Dietz 1998, 433-5.

94 Miller and Summers 2007, 738.

95 For some additional examples see http://www.start. umd.edu/research-projects/empirical- analysis-iedattacks; http://www.start.umd.edu/news/discussionpoint-embrace-big-data-dont-ignore-human-elementdata-coding.

96 http://www.princeton.edu/ jns/papers/ BFJRS_2014_PK_Data_Final.pdf.

97 Rose 2012.

98 Gunitsky, 2015.

\section{Supplementary Materials}

- The Military Videogame Advertisement (MVA) Dataset - Coding Guide

- The Military Videogame Advertisement (MVA) Dataset: Version 1.7-Codebook

http://dx.doi.org/10.1017/S1537592716002887

\section{References}

Åhäll, Linda. 2012. “The Writing of Heroines:

Motherhood and Female Agency in Political Violence." Security Dialogue 43(4): 287-303.

Åhäll, Linda and Stefan Borg. 2013. "Predication,

Presupposition and Subject-Positioning." In Critical 
Approaches to Security: An Introduction to Theories and Methods, ed. Linda J. Shepherd. London: Routledge.

Åhäll, Linda. 2015. "The Hidden Politics of Militarization and Pop Culture as Political Communication." In Popular Culture and World Politics: Theories, Methods, Pedagogies, ed. Federica Caso and Caitline Hamilton. Bristol: E-International Relations.

Ahmed, Amel and Rudra Sil. 2012. "When Multi-Method Research Subverts Methodological Pluralism—or, Why We Still Need Single-Method Research." Perspectives on Politics 10(4): 935-53.

Amoore, Louise. 2007. "Vigilant Visualities: The Watchful Politics of the War on Terror." Security Dialogue 38(2): 215-32.

Andersen, Robin. 2006. A Century of Media, A Century of War. New York: Peter Lang.

Aradau, Claudia and Jef Huysmans. 2013. "Critical Methods in International Relations: The Politics of Techniques, Devices and Acts." European Journal of International Relations 20(1): 596-61.

Bacevich, Andrew J. 2005. The New American Militarism: How Americans Are Seduced by War. New York: Oxford University Press.

Barakso, Maryann, Daniel M. Sabet, and Brian Schaffner. 2014. Understanding Political Science Research Methods: The Challenge of Inference. London: Routledge.

Baudrillard, Jean. 1995. The Gulf War Did Not Take Place. Sydney: Power Publications.

Beasley, Berrin and Tracy Collins Standley. 2002. "Shirts vs. Skins: Clothing as an Indicator of Gender Role Stereotyping in Video Games." Mass Communication and Society 5(3): 279-93.

Berg-Schlosser, Dirk. 2012. Mixed Methods in Comparative Politics: Principles and Applications. New York: Palgrave Macmillan.

Bernazzoli, Richelle M. and Colin Flint. 2009. "Power, Place, and Militarism: Towards a Comparative Geographic Analysis of Militarization." Geography Compass 3(1): 393-411.

. 2010. "Embodying the Garrison State? Everyday Geographies of Militarization in American Society." Political Geography 29(3): 157-66.

Bleiker, Roland. 2003. "Learning from Art: A Reply to Holden's 'World Literature and World politics." Global Society 17(4): 415-28.

. 2009. Aesthetics and World Politics. New York: Palgrave.

. 2015. "Pluralist Methods for Visual Global

Politics." Millenium: A Journal of International Studies 43(3): 872-90.

Boggs, Carl and Tom Pollard. 2006. "Hollywood and the Spectacle of Terrorism." New Political Science 28(3): 335-51.

2007. The Hollywood War Machine: US Militarism and Popular Culture. Boulder, CO: Paradigm.
Brady, Henry E., David Collier, and Jason Seawright. 2004. "Refocusing the Discussion of Methodology." In Rethinking Social Inquiry: Diverse Tools, Shared Standards, ed. H.E. Brady, and David Collier. New York: Rowman \& Littlefield.

Brady, Henry and David Collier. 2006. "Toward a Pluralistic Vision of Methodology." Political Analysis 14(3): 353-68.

Campbell, David. 2007. "Geopolitics and Visuality: Sighting the Darfur Conflict." Political Geography 26(4): 357-82.

Chan, Dean. 2005. "Playing with Race: The Ethics of Racialized Representations in E-Games." International Review of Information Ethics 4(12): 24-30.

Cynthia, Cockburn. 2010. "Militarism and War." In Gender Matters in Global Politics: A Feminist Introduction to International Relations, ed. Laura J. Shepherd. London: Routledge.

Collier, David and Henry Brady. 2004. Rethinking Social Inquiry: Diverse Tools, Shared Standards. New York: Rowman \& Littlefield Publishers, Inc.

Crowe, Jonathan and Kylie Weston-Scheuber. 2013. Principles of International Humanitarian Law. Northampton, MA: Edward Elgar.

Dalby, Simon. 2008. "Warrior Geopolitics: Gladiator, Black Hawk Down and The Kingdom of Heaven." Political Geography 27(4): 439-55.

Dauphinée, Elizabeth. 2007. "The Politics of the Body in Pain: Reading the Ethics of Imagery." Security Dialogue 38(2): 139-55.

Davies, Matt and Simon Philpott. 2012. "Militarization and Popular Culture." In The Marketing of War in the Age of Neo-Militarism, ed. K. Gouliamos and Christos Kassimeris. New York: Routledge.

Der Derian, James. 2009. Virtuous War: Mapping the Military-Industrial-Media-Entertainment Network. New York: Routledge.

Dietz, Tracy L. 1998. "An Examination of Violence and Gender Role Portrayals in Video Games: Implications for Gender Socialization and Aggressive Behavior." Sex Roles 38(5-6): 425-42.

Dittmer, Jason. 2010. Popular Culture, Geopolitics, and Identity. Plymouth: Rowman \& Littlefield.

Dodds, Klaus. 2007. "Steve Bell's Eye: Cartoons, Geopolitics and the Visualization of the "War on Terror." Security Dialogue 38(2): 157-77.

_. 2008. "'Have You Seen Any Good Films Lately?' Geopolitics, International Relations and Film." Geography Compass 2(2): 476-94.

. 2008. "Hollywood and the Popular Geopolitics of the War on Terror." Third World Quarterly 29(8): 1621-37.

Dyer-Witherford, Nick and Greig De Peuter. 2009. Games of Empire: Global Capitalism and Video Games. Minneapolis: University of Minnesota Press. 
Enloe, Cynthia. 2004. "Wielding Masculinity inside Abu Ghraib: Making Feminist Sense of an American Military Scandal." Asian Journal of Women's Studies 10(3): 89-102.

Feldman, Allen. 2009. "The Structuring Enemy and Archival War." PMLA 124(5): 1704-13.

Fischer, Mia. 2014. "Commemorating 911 NFL Style, Insights into America's Culture of Militarism." Journal of Sport and Social Issues 38(3): 199-221.

Geddes, Barbara. 2003. Paradigms and Sand Castles. Ann Arbor: University of Michigan Press.

Geyer, Michael. 1989. "The Militarization of Europe, 1914-45." In The Militarization of the Western World, ed. John R. Gillis. New Brunswick and London: Rutgers University Press.

Ghosn, Faten, Glenn Palmer, and Stuart A. Bremer. 2004. "The MID3 Data Set, 1993-2001: Procedures, Coding Rules, and Description." Conflict Management and Peace Science 21(2): 133-54.

Gillis, John. 1989. "Introduction.” In The Militarization of the Western World, ed. John R. Gillis. New Brunswick and London: Rutgers University Press.

Gleditsch, Nils Petter, Peter Wallensteen, Mikael Eridsson, Margareta Sollenberg, and Havard Strand. 2002. "Armed Conflict 1946-2001: A New Dataset." Journal of Peace Research 39(5): 615-37.

Gonzales, Roberto J. 2010. Militarizing Culture: Essays on the Warfare State. Walnut Creek, CA: Left Coast Press.

Goemans, Henk E., Kristian Skrede Gleditsh, and Giacomo Chiozza. 2009. "Introducing Archigos: A Dataset of Political Leaders." Journal of Peace Research 46(2): 269-83.

Graham, Stephen. 2012. "When Life Itself Is War: On the Urbanization of Military and Security Doctrine." International Journal of Urban and Regional Research 36(1): 136-55.

Gregg, Robert W. 1998. International Relations on Film. London: Lynne Rienner.

1999. "The Ten Best Films about International Relations." World Policy Journal 16(2): 129-134.

Gunitsky, Seva. 2015. "Corrupting the Cyber-Commons: Social Media as a Tool of Autocratic Stability." Perspectives on Politics 13(1): 42-54.

Hansen, Lene. 2011. "Theorizing the Image for Security Studies: Visual Securitization and the Muhammad Cartoon Crisis." European Journal of International Relations 17(1): 51-74.

Halperin, Sandra and Oliver Heath. 2012. Political Research: Methods and Practical Skills. Oxford: Oxford University Press.

Hess, Aaron. 2007. “'You Don't Play, You Volunteer:' Narrative Public Memory Construction in Medal of Honor: Rising Sun." Critical Studies in Media Communication 24(4): 339-56.
Hood, Christopher. 2011. "Commentary: From FOI World to WikiLeaks World: A New Chapter in the Transparency Story?" Governance 24(4): 635-38.

Höglund, Johan. 2008. "Electronic Empire: Orientalism Revisited in the Military Shooter." Game Studies 8(1): Available at http://gamestudies.org/0801/articles/hoeglund.

Holland, Jack. 2011. "'When You Think of the Taliban, Think of the Nazis:' Teaching Americans '9-11' in NBC's 'The West Wing." Millennium-Journal of International Studies 40(1): 85-106.

Howardiff, John W. and Laura C. Prividera. 2008. "The Fallen Woman Archetype: Media Representations of Lynndie England, Gender, and the (Ab)uses of U.S. Female Soldiers." Women's Studies in Communication 31(3): 287-311.

Huntemann, Nina B. and Matthew Thomas Payne. 2010. "Introduction." In Joystick Soldiers: The Politics of Play in Military Video Games, ed. Nina Huntemann and Matthew Thomas Payne. New York: Routledge.

International Telecommunications Union. 2015. 'ICT Facts and Figures: The World in 2015.' Available at https:/www.itu.int/en/ITU-D/Statistics/Documents/ facts/ICTFactsFigures2015.pdf. Geneva: ITU.

Jansz, Jeroen and Raynel G. Martis. 2007. “The Lara Phenomenon: Powerful Female Characters in Video Games." Sex Roles 56(3-4): 141-48.

Kellner, Douglas. 2004. "9/11, Spectacles of Terror, and Media Manipulation: A Critique of Jihadist and Bush Media Politics." Critical Discourse Studies 1(1): 41-64. Khatib, Lina. 2012. Image Politics in the Middle East: The Role of the Visual in Political Struggle. London: I.B. Tauris.

King, Gary, Robert Keohane, and Sidney Verba. 1994. Designing Social Inquiry. Princeton, NJ: Princeton University Press.

Kohn, Richard H. 2009. "The Danger of Militarization in an Endless 'War' on Terrorism." Journal of Military History 73(1): 177-208.

Kundnani, Arun. 2004. "Wired for War: Military Technology and the Politics of Fear." Race and Class 46(1): 116-25.

Lacy, Mark J. 2001. "Cinema and Ecopolitics: Existence in the Jurassic Park." Millenium: A Journal of International Studies 30(3): 635-45.

2003. "War, Cinema, and Moral Anxiety." Alternatives 28(5): 611-36.

Lutz, Catherine. 2002. "Making War at Home in the United States: Militarization and the Current Crisis." American Anthropologist 104(3): 723-35.

Mahoney, James and Gary Goertz. 2006. "A Tale of Two Cultures: Contrasting Quantitative and Qualitative Research.” Political Analysis 14(3): 227-49.

Mantello, Peter. 2012. "Playing Discreet War in the US: Negotiating Subjecthood and Sovereignty through 
Special Forces Video Games." Media, War \& Conflict 5(3): 269-83.

Maradin, Nicholas R. 2013. "Militainment and Mechatronics: Occultio and the Veil of Science Fiction Cool in the United States Air Force." Ethics and Information Technology 15(2): 77-86.

Marsh, David and Gerry Stoker, eds. 1995. Theory and Methods in Political Science. New York: Palgrave Macmillan.

McInnes, Colin. 2002. Spectator Sport War: The West and Contemporary Conflict. Boulder, CO: Lynne Rienner.

McNabb, David. 2010. Research Methods for Political Science. New York: M.E. Sharpe.

Miller, Monica K. and Alicia Summers. 2007. "Gender Differences in Video Game Characters' Roles, Appearances, and Attire as Portrayed in Video Game Magazines." Sex Roles 57(9-10): 733-42.

Möller, Frank. 2007. "Photographic Interventions in Post9/11 Security Policy." Security Dialogue 38(2): 179-96.

Orr, Jackie. 2004. "The Militarization of Inner Space." Critical Sociology 30(2): 451-81.

Poole, Steven. 2004. Trigger Happy: The Inner Life of Videogames, revised edition, Afterword. London: Fourth Estate. Available from: http://stevenpoole.net/ trigger-happy/afterword-2004/.

Power, Marcus. 2007. "Digitized Virtuosity: Video War Games and Post-9/11 Cyber-Deterrence." Security Dialogue 38(2): 271-88.

Protevi, John. 2009. Political Affect: Connecting the Social and the Somatic. Minneapolis: University of Minnesota Press.

Provenzo, Eugene F. 1991. Video Kids: Making Sense of Nintendo. Cambridge, MA: Harvard University Press.

Rech, Matthew F. 2014. "Be Part of the Story: A Popular Geopolitics of War Comics Aesthetics and Royal Air Force Recruitment." Political Geography 39: 36-47.

Robinson, Nick. 2012. "Videogames, Persuasion and the War on Terror: Escaping or Embedding the Military-Entertainment Complex?” Political Studies 60(3): 504-22.

2015. "Have You Won the War on Terror? Military Videogames and the State of American Exceptionalism." Millennium: Journal of International Studies 43(2): 450-70.

. 2016. "Militarism and Opposition in the Living

Room: The Case of Military Videogames." Critical Studies on Security. Early View: http://dx.doi.org/ 10.1080/21624887.2015.1130491.

Rose, Gillian. 2012. Visual Methodologies: An Introduction to Researching with Visual Materials. 3d ed. London: Sage.

Rowley, Christina. 2010. "Popular Culture and the Politics of the Visual." In Gender Matters in Global Politics: A Feminist Introduction to International Relations, ed. Laura J. Shepherd. London: Routledge.
Rowley, Christina and Jutta Weldes. 2012. "The Evolution of International Security Studies and the Everyday." Security Dialogue 43(6): 513-30.

Salter, Michael. 2014. "Toys for the Boys? Drones, Pleasure and Popular Culture in the Militarisation of Policing." Critical Criminology 22(2): 163-77.

Scharrer, Erica. 2004. "Virtual Violence: Gender and Aggression in Video Game Advertisements." Mass Communication and Society 7(4): 393-412.

Schedler, Andreas 2012. "Judgment and Measurement in Political Science.” Perspectives on Politics 10(1): 21-36.

Schulzke, Marcus. 2012. "Campaigning in the Digital World: Obama's Use of Dynamic Advertisements." Journal of Information Technology and Politics 9(4): 338-51. 2013a. "Being a Terrorist: Video Game Simulations of the Other Side of the War on Terror." War, Media \& Conflict 6(3): 207-20.

2013b. "Rethinking Military Gaming: America's Army and Its Critics." Games and Culture 8(2): 59-76. 2013c. "The Virtual War on Terror: Counterterrorism Narratives in Video Games." New Political Science 35(4): 586-603.

2014. "Simulating Terrorism and Insurgency: Video Games in the War of Ideas." Cambridge Review of International Affairs 27(4): 627-43.

Shapiro, Michael J. 2009. Cinematic Geopolitics. New York: Routledge. 2013. Studies in Trans-Disciplinary Method: After the Aesthetic Turn. London: Routledge.

Shaw, Ian Graham Ronald. 2010. "Playing War." Social \& Cultural Geography 11(8): 789-803.

Shepherd, Laura J. 2008. "Visualising Violence: Legitimacy and Authority in the "War on Terror." Critical Studies on Terrorism 1(2): 213-226.

. 2013. Gender, Violence and Popular Culture: Telling Stories. London: Routledge.

Sherry, Michael S. 1995. In the Shadow of War: The United States Since the 1930s. New Haven, Conn: Yale University Press.

Shim, David. 2014. Visual Politics and North Korea: Seeing Is Believing. London: Routledge.

Šisler, Vit. 2008. "Digital Arabs: Representation in Video Games." European Journal of Cultural Studies 11(2): 203-20.

Sjolander, Clair Tyrenne and Kathryn Trevenen. 2010. "One of the Boys? Gender Disorder in Times of Crisis." International Feminist Journal of Politics 12(2): 158-76.

Stahl, Roger. 2006. "Have You Played the War on Terror?" Critical Studies in Media Communication 23(2): 112-30.

2009. "Why We 'Support the Troops:' Rhetorical Evolutions." Rhetoric \& Public Affairs 12(4): 533-70. 2010. Militainment, Inc.: War, Media, and Popular Culture. Abingdon: Routledge. 
Stavrianakis, Anna and Jan Selby. 2012. "Militarism and International Relations in the Twenty-first Century." In Militarism and International Relations: Political Economy, Security, Theory, ed. Anna Stavrianakis and Jan Selby. London: Routledge.

Thomson, Matthew. 2009. "From Underdog to Overmatch: Computer Games and Military Transformation." Popular Communication: The International Journal of Media and Culture 7(2): 92-106.

Van Veeren, Elspeth. 2009. "Interrogating 24: Making Sense of US Counter-terrorism in the Global War on Terrorism." New Political Science 31(3): 361-84.
Weber, Cynthia. 2001. "The Highs and Lows of Teaching IR Theory: Using Popular Films for Theoretical Critique." International Studies Perspectives 2(3): 281-87. 2006. Imagining America at War: Morality, Politics, and Film. London: Routledge.

- 2014. International Relations Theory: A Critical Introduction. 4th ed..London: Routledge.

Wetta, Frank Joseph and Martin A. Novelli. 2003. “'Now a Major Motion Picture:' War Films and Hollywood's New Patriotism." Journal of Military History 67(3): 861-82.

Zehfuss, Maja. 2011. "Targeting: Precision and the Production of Ethics." European Journal of International Relations 17(3): 543-66. 